\title{
«МОЛОДЕЖНАЯ» ИЛИ «КОМСОМОЛЬСКАЯ» ЭКОНОМИКА: ВЗГЛЯД ЧЕРЕЗ 30 ЛЕТ
}

\author{
А. А. Мелитонян \\ Союз филокартистов России, г. Москва
}

Аннотация: В статье анализируются вопросы молодежной или комсомольской экономики 1980-х годов в истории СССР, которая рассматривается как комплексное явление.

Ключевые слова: молодежная экономика; комсомольская экономика; комсомол; ВЛКСМ; история СССР

\section{“YOUTH” OR “KOMSOMOL” ECONOMY: 30 YEARS LATER}

\author{
A. A. Melitonyan \\ Russian Postcard Union
}

Аннотация: The paper analyses issues of youth or Komsomol economy of the 1980s in the history of the USSR, which is considered a complex phenomenon.

Ключевые слова: youth есопоту; Komsomol economy; Komsomol; All-Union Leninist Young Communist League; history of the USSR

В своей статье я затрону вопросы, касающиеся такого еще недостаточно изученного социокультурного и политико-экономического феномена, как «молодежная» или «комсомольская» экономика 1980-х годов. Начало этому комплексному явлению было положено в конце 1970-х годов, его наибольший расцвет пришелся на период 1986-1991 годов, а исчезновение связано с просчетами в определении общего подхода к поддержке экономических инициатив молодежи в социокультурной сфере, а также в области оказания услуг и развития производства, со сменой отношения руководства Коммунистической партии и государства к предпринимательству в молодежной среде, изменением законодательства, прекращением деятельности ВЛКСМ, распадом СССР и последовавшей сменой приоритетов в экономической политике в постсоветской России.

Рассмотрению вопросов развития экономических и социально-культурных инициатив молодежи указанного периода посвящены статьи, опубликованные в периодических и публицистических изданиях в годы пере- 
стройки в СССР 1985-1991 годов, несколько научных работ, в том числе В. М. Кононова (Кононов, 1988) и автора этой статьи (Мелитонян, 1996, 1997, 2005), а также довольно неоднозначные современные аналитические материалы в сети Интернет.

В указанных трудах анализируются вопросы развития социальной инициативы молодежи, раскрываются последовательность развития, особенности, достижения и проблемы «молодежной» экономики 1980-х годов, использовавшей для своего становления и развития, с одной стороны, существовавшую советскую нормативно-правовую базу при одновременном ее корректировании со стороны государства и включенных в процесс реформирования общественно-политических и общественных организаций, а с другой, являвшейся, вместе с другими формами экономических инноваций того времени, существенной частью, как оказалось впоследствии, слишком короткого переходного периода от плановых норм ведения хозяйствования к рыночным, происходившего на фоне кардинальных общественно-политических и социокультурных изменений.

«Комсомольская» экономика стала одной из форм апробации эффективности хозрасчетных экономических механизмов, предшествовавших рыночным отношениям. Она, в том числе, повлияла на формирование подходов к последовавшему экономическому реформированию, создала определенные основы для конкурентной борьбы за счет вовлечения в нее большой части мотивированной молодежи и развития экономики, базирующейся на собственных силах предпринимателей, использовавших не столько предоставленные материальные ресурсы, но прежде всего, новые возможности и подходы для развития бизнеса, очень часто начиная свою деятельность «с нуля». Молодежные центры и предприятия комсомола ставили своей целью, в том числе, решение социальных проблем за счет разработки механизмов социальной ответственности, одновременно способствовав возникновению новой формации предпринимателей, ряд из которых, получив первый опыт работы в условиях самофинансирования середины-конца 1980-х, в начале 1990-х годов возглавил крупные бизнес структуры, а к середине и концу 1990-х уже входил в число известных бизнесменов Российской Федерации.

Однако, одновременно, в силу ряда допущенных недоработок в рассмотрении места и роли молодежных хозяйственных формирований в общей системе хозяйствования или в силу иных причин, связанных, в том числе, с активным вхождением в экономику самого конца 1980-х — начала 1990-х годов ряда представителей номенклатуры, та же «комсомольская» экономика является притчей во языцех при критике современного бизнеса, его ориентированности на олигархический капитал или анализе причин гиперинфляционных процессов в отечественной экономике переходного периода.

В данной статье я считаю необходимым еще раз, по прошествии тридцати лет с момента возникновения понятия «молодежная» или «комсо- 
Научные труды Московского гуманитарного университета 2018 № 6

мольская» экономика, проанализировать ряд аспектов этого явления, дать оценку деятельности комсомола по созданию и поддержке инновационных хозрасчетных формирований, напомнить о самом факте существования «молодежной» экономики с попытками самоидентификации и самореализации в середине-конце 1980-х годов большой прослойки молодых предпринимателей, пришедших, в большинстве, из первичных комсомольских организаций и действовавших как в творческих, таки в производственных сферах и сфере услуг.

Комсомол 1980-х годов был именно той организацией, которая, по роду деятельности, целям и задачам, будучи наиболее подготовленной к восприятию инициатив молодежи и, одновременно, обладая опытом хозяйствования, приступила к созданию, но, в силу ряда причин, не смогла сформировать своего рода класс мелких и средних предпринимателей, необходимый для стабильного социально-экономического роста в рыночной экономике. В то же время, благодаря комсомолу в условиях перестройки появилась возможность для самореализации большой части молодежи в культурной, общественной и производственной сферах, в ряде областей хозяйствования.

Предпосылки к ведению самостоятельной социально-экономической деятельности, развивавшейся в связке с государственной, проявились у комсомола еще в 1920 г., когда молодежь впервые на возмездной основе была привлечена к участию в сельскохозяйственных работах. Конец 1950-х годов ознаменовался началом активной деятельности студенческих отрядов. Их участники, получая вознаграждение за свой труд, одновременно, как пишут в Интернете, получали навыки коллективизма и коммунистического воспитания. В начале 1970-х годов зародилось и начало активно развиваться движение молодежных жилых комплексов. Особенно активным развитие МЖК стало в 1985-1986 годах, после выхода ряда правительственных постановлений. В 1985 году в Новосибирске при поддержке ЦК ВЛКСМ был создан хозрасчетный «Фонд молодежных инициатив», имевший возможность совершать коммерческие сделки. С началом перестройки комсомол активно включился не только в процесс общественно-политического и социокультурного, но и экономического реформирования. За очень короткий срок с 1986 по 1990 годы, при кураторстве со стороны коммунистической партии, государственными органами, ВЦСПС и ЦК ВЛКСМ были выработаны и приняты регламентирующие документы, позволившие всерьез говорить о самостоятельной «молодежной» или «комсомольской» экономике сначала в сфере культуры, а затем - в производственной и иных сферах. В марте 1987 года была образована единая общегосударственная система научно-технического творчества молодежи, позволявшая заключать крупные хозяйственные договоры, в том числе, на научно-исследовательские работы. 17 апреля 1987 года Генеральный секретарь ЦК КПСС М.С. Горбачев, выступая на ХХ съезде ВЛКСМ отметил: «...Давайте договоримся о том, что комсомолу 
до всего есть дело в стране... ...сегодня, как никогда, есть общественная необходимость в том, чтобы комсомол действовал как активная политическая организация молодежи» (Горбачев, 1987). Исходя из этого и признавая, что «комсомольская наука» не располагает «готовыми рецептами перестройки» было признано, что «первичная организация, комитет комсомола вправе, исходя из общих задач, сами выбирать из всего арсенала форм и методов работы те из них, которые считают наиболее эффективными» (ХХ съезд ..., 1948). Поддержке социокультурных инициатив и экономической деятельности был отдан приоритет. В том же 1987 году ЦК ВЛКСМ утвердил Положение о хозрасчетном молодежном объединении. Активное нормотворчество в различных областях деятельности на фоне льготного налогообложения и ряда привилегий для комсомольских хозяйственных структур сопровождалось взрывным характером инициатив в социокультурной, производственной сферах и сфере удовлетворения потребностей молодежи и всего населения страны в разнообразных услугах. В 1988 году появляются ряд постановлений ЦК КПСС и Совета министров СССР, расширявших возможности комсомола в ведении хозяйственной и внешнеэкономической деятельности. В 1989 году выходит Положение о предприятии комсомола. Уже через год, по данным созданного в конце 1988 года Координационно-методического центра ЦК ВЛКСМ по работе с молодежными объединениями (КМЦ ЦК ВЛКСМ), в СССР насчитывалось около четырех тысяч молодежных культурных и иных инновационных центров при комитетах комсомола, в каждом из которых на постоянной основе работало от 3-5 до многих десятков молодых людей. Т. е. за чрезвычайно короткий исторический период на основе созданных и принятых нормативных актов в стране, на принципах хозрасчета, самообеспечения и самозанятости (т.е. формирования рабочих мест самими инновационными организациями под выполнение конкретных, обеспеченных заказами работ), оказались трудоустроенными до ста тысяч молодых людей. И это только в одном из параллельно развивавшихся в системе комсомола направлений деятельности, без учета НТТМ, МЖК и студенческих строительных отрядов. Одновременно с комсомольскими, действовали молодежные предприятия и организации, использовавшие положения законов СССР «О государственном предприятии (объединении)», «Об индивидуальной трудовой деятельности», «О кооперации в СССР».

Таким образом, можно констатировать, что, в целом, в процесс реформирования экономики, развития предпринимательства, самоорганизации экономической жизни и ее самообеспечения были вовлечены на основе постоянной занятости несколько сотен тысяч молодых людей в возрасте от 18 до 35 лет. Помимо этой, наиболее активной в социокультурном и социально-экономическом плане части молодежи, вовлеченными в этот процесс оказывались и исполнители хозяйственных договоров, и члены семей молодых культуртрегеров и предпринимателей, и их знакомые и друзья. А это уже говорит о вероятной цифре в несколько миллионов человек, ощущав- 
Научные труды Московского гуманитарного университета 2018 № 6

ших на себе влияние перемен. И что крайне важно, это поистине революционное движение, состоявшее из молодых людей, поверивших в возможность социокультурных и экономических преобразований при существовавшем на то время общественно-политическом строе сформировалось всего за три-четыре года! Результаты не замедлили сказаться и в политическом, и в экономическом, и в культурном, и даже в демографическом плане: увеличилось число вступающих в комсомол, повысился объем оказания платных услуг населению, у молодежи появилась возможность получать хорошую зарплату, на более прогрессивных основаниях развивались производственная деятельность, культурно-творческая жизнь, повысилась рождаемость...

В докладной записке КМЦ ЦК ВЛКСМ на имя первого секретаря ЦК ВЛКСМ В. И. Мироненко указывалось, что «совокупный оборот молодежных центров в 1989 году может составить до 1 млрд. рублей ... Если принять объем выполненных работ центрами НТТМ на уровне 1,5 млрд. рублей в год, совокупный оборот молодежных хозяйственных формирований в 1989 году может составлять до 2,5-3 млрд рублей»․․ Комсомол, по прежнему выполняя политические задачи, в определенном смысле, стал превращаться и в некий хозяйственно-экономический комплекс, своеобразное межотраслевое ведомство со своими коммерческими структурами, в том числе банковскими и внешнеэкономическими, с центрами управленческого консультирования и аудиторских услуг.

В 1989 году с участием молодежных центров и иных хозяйственных формирований комсомола начали создаваться ассоциации молодых предпринимателей: Ассоциация молодых руководителей предприятий СССР, Ассоциация творческих центров, организаций и предприятий, Ассоциация социально-экономического развития (АСЭР). В 1990 году был образован Московский фонд поддержки малого предпринимательства, в деятельности которого немалую роль играли представители «молодежной» экономики.

В докладе: «О современном состоянии хозяйственно-экономической деятельности ВЛКСМ», написанном в рамках подготовки к созданию АСЭР говорится: «...На фоне все возрастающей напряженности, возникшие и активизирующиеся общественные движения предпринимают попытки путем мобилизации сил снизу создать прообразы самодостаточных, саморегулирующихся структур, в том числе в сфере общественного производства, где... правоспособность определялась бы объективными потребностями... Движение, зародившееся в конце 70-х годов в виде создания фондов молодежной инициативы - объединений молодежных клубов - добровольных общественных организаций молодежи, развивалось последовательно от добровольных обществ и любительских объединений к предприятиям комсомола...»².

На этом этапе были выявились и серьезные проблемы в работе мо-

\footnotetext{
${ }^{1}$ Личный архив А. А. Мелитоняна.

2 Там же.
} 
лодежных хозяйственных формирований, связанные с отсутствием полноценного государственного статуса, с плохой разработанностью механизмов оперативного регулирования деятельности предприятий комсомола, отсутствием должной нормативной базы, выявлявшимися нарушениями, с низкой подготовкой кадров и целым рядом других факторов. При ЦК ВЛКСМ был создан Программный совет для выработки целостной концепции хозяйственной деятельности ВЛКСМ, которому, вместе с Управлением делами ЦК ВЛКСМ было поручено внести на рассмотрение Секретариата ЦК ВЛКСМ проект постановления Совета Министров СССР, ЦК ВЛКСМ и ВЦСПС по обеспечению деятельности молодежных хозяйственных формирований. Руководящими органами комсомола отмечалась «необходимость осуществить меры по приведению деятельности хозяйственных подразделений ВЛКСМ в соответствие с требованиями Устава комсомола и ликвидировать условия, приводящие к нарушению законодательства СССР, дискредитирующих развитие комсомольской экономики...»

Однако для нас важен другой аспект развития процесса. Как уже указывалось выше, в ходе стремительного развития экономической активности предприятий комсомола всего за несколько лет сформировалась достаточно большая прослойка молодых предпринимателей низового уровня, которая пользуясь возможностями и налоговыми привилегиями комсомола, получила в свои руки достаточно существенный капитал, но, самое главное, уверенность в возможности развития общественно-государственного и частного предпринимательства в стране и перспективе создания независимых фирм с большими доходами. Выплата налогов государству для части молодежных центров и предприятий комсомола к концу 1980-х годов уже не была проблемой, поскольку все они так или иначе делали отчисления от своей прибыли. Ряд молодых предпринимателей, не чувствуя быстрого решения как общих (обозначение места хозяйственных подразделений комитетов комсомола в народном хозяйстве, определение правоспособности понятия «предприятие ВЛКСМ», обеспечение социальных гарантии для членов трудовых коллективов и др. - А. М.), так и частных вопросов своего существования и развития, по сути, после достижения определенного статуса, перестал нуждаться в комсомольской «опеке». Молодежные предприятия, как им представлялось, были готовы пуститься в «самостоятельное плавание». Они почувствовали свою силу и, представляя значительную часть наиболее активной молодежи, стремились, на фоне общего развития в обществе гражданской активности и гласности, выступать на равных с руководящими органами ВЛКСМ позициях, в том числе, и в вопросах формирования общественно-политической, экономической и социокультурной повесток дня.

С другой стороны, комсомольские организации, на фоне все более явственных тенденций пересмотра политических и экономических основ жизнедеятельности общества и на фоне внутренних проблем самого комсо- 
Научные труды Московского гуманитарного университета 2018 № 6

мола, как политической организации, имели в руках принадлежащие им на праве собственности коммерческие организации, в уставах которых было четко прописана их ориентированность на удовлетворение социокультурных потребностей молодежи, в том числе, за счет направления на эти цели определенной части заработанных средств от коммерческой деятельности. Плюс к этому, работа ряда структурообразующих хозяйствующих субъектов «комсомольской экономики», использующих собственность и средства комсомола, стала приносить прибыль. А это была надежда и определенная гарантия будущего...

В 1989 году в своей статье «Комсомольская экономика» в журнале «Молодой коммунист» заведующий отделом рабочей молодежи ЦК ВЛКСМ С. Лямин писал: «... комсомольская экономика - это практика самостоятельного хозяйствования, создания комсомольскими организациями или под их эгидой хозрасчетных культурно-просветительских, спортивно-оздоровительных центров, сервисных, посреднических, производственных и иных предприятий; получение прибыли, которая используется для удовлетворения социальных потребностей молодежи» (Лямин, 1989: 39). К слову сказать, для большинства молодежных центров и предприятий комсомола решение социальных вопросов за счет хозяйственной деятельности всегда являлось целью развития.

Возникло общее ощущение неудовлетворенности. Итогом отсутствия целеполагания, не разработанности механизмов координации, отсутствия взаимного учета интересов, скоординированной с государством политики экономического развития и воспитания менеджеров нового поколения (предпринимательских курсов и целевых программ подготовки молодых руководителей экономических предприятий комсомола практически не было создано. - А. М.) стали взаимное недопонимание, недоверие, препятствие развитию ассоциаций молодежных центров, снижение возможностей эффективного взаимовлияния на процесс структурных преобразований.

Результат не замедлил сказаться. Не придав должного значения или целенаправленно не замечая перспективности инициативного движения, не сформировав из этой части инициативных молодых людей необходимую для развития новой государственной рыночной экономики прослойку предпринимателей низового и среднего звена, использующих не только уже имеющиеся ресурсы, но и создающих новый продукт, сделав ставку исключительно на коммерциализацию и реорганизацию уже существующих предприятий с существующими руководителями, неосознанно или осознанно дав дорогу «номенклатурному капитализму», партийное руководство и государственные органы, пользуясь тем, что и сам комсомол до конца не определился с целеполаганием в отношении «молодежной» экономики, резко изменило свое отношение к «комсомольскому предпринимательству».

После выступления М. С. Горбачева на ХХІсъезде комсомола в апреле 1990 года, в котором он, поддержав системы НТТМ и МЖК, выразил опа- 
сение, связанное с «втягиванием» комсомольских предприятий в кооперативную и «перекупную» деятельность и высказался за «необходимость найти грань» (Идти вместе ... , 1990), налоговые льготы для молодежных центров и предприятий комсомола были отменены. Многие «обремененные» не только необходимостью, но и искренней потребностью решать не только коммерческие, но и социальные задачи комсомольские хозяйственные формирования оказались, благодаря этому, на одной ступени с быстро реструктуризирующимися российскими государственными организациями, обладавшими огромными ресурсами, но отнюдь не нацеленными на выполнение социальных функций, с гигантами рыночной экономики, возникающими в банковской, биржевой, торговой и иных сферах.

В августе 1991 года ВЛКСМ прекратил свою деятельность. Вместе с комсомолом перестали действовать и его предприятия. Молодые предприниматели были поставлены перед фактом необходимости завершения своей работы или перехода на иные условия хозяйствования. В декабре1991 года прекратил свое существование СССР. Бывшие республики, еще до этого момента ставшие независимыми государствами, стали самостоятельно развивать свои экономики и судьба молодежных экономических формирований в них мне неизвестна. Наиболее успешные бывшие молодежные центры и предприятия комсомола в России, составляющие по моим оценкам, не более пяти-семи процентов от общего количества созданных в свое время в РСФСР подобных организаций, остались «на плаву», а некоторые даже значительно преуспели. Одновременно, накопив капитал за счет деятельности собственных или подконтрольных компаний, сформировали коммерческие структуры ряд руководителей комсомольских органов, центров НТТМ и других хозяйствующих структур, влившись в политическую и бизнес элиту и начав определять дальнейшие векторы развития политики, экономики и социальной деятельности нового государства — Российской Федерации.

Абсолютное же большинство российских молодых руководителей, не успевших набрать нужные «обороты» или ставивших своей целью не столько заработок, сколько решение насущных, в том числе, социальных задач, ушли из бизнеса. Некоторые бывшие руководители и сотрудники молодежных центров продолжает и сейчас работать в качестве индивидуальных предпринимателей или имеют небольшие компании. Многие директора так и не смогли вернуться в активную фазу деятельности, а некоторые, и вовсе, после нескольких лет немыслимого напряжения, стали социально безразличными или даже, под действием стрессов и жизненных обстоятельств, ушли из жизни...

Анализируя консолидированный потенциал развития молодежных центров, иных хозяйственных организаций и предприятий комсомола, следует отметить, что с прекращением их координируемой не только законами хозяйственной деятельности, но, прежде всего, общественно-политическим целеполаганием работы был потерян практически единственный, не наце- 
Научные труды Московского гуманитарного университета 2018 № 6

ленный исключительно на извлечение прибыли довольно значительный человеческий ресурс для развития социально ориентированной экономики России даже при переходе страны в 1991 году к иному общественно-политическому строю. Именно «молодежные» предприятия, действовавшие как в сфере «комсомольской» экономики, так и использовавшие другие возможности для развития, вместе с другими заинтересованными и активными субъектами экономики были способны действовать в направлении формирования экономики производства и оказания услуг, имеющей своей целью производство не только продукции, но и социальных благ. Отказавшись от того, чтобы поддержать молодых инициативных предпринимателей и сделав ставку на иные решения, властные структуры того времени внедрили экономику потребления, экономику обогащения для одних и выживания для других. Общество и государство вернулись к обсуждению положений о социальной ответственности бизнеса, к вопросам социального партнерства только через два десятилетия...

В подтверждение своих слов о социальной направленности деятельности молодежных центров и предприятий комсомола приведу лишь несколько примеров. В «Примерном положением о молодежном центре» говорилось, что основной целью его создания «является наиболее полное удовлетворение общественно значимых духовных потребностей молодежи, выявление, развитие и реализация инициатив, способствующих формированию всесторонней, гармонически развитой личности» ${ }^{1}$. Целями деятельности АСЭР (1989) являлись «разработка и апробация инновационных моделей и механизмов правового регулирования и экономического взаимодействия мобильных хозяйственных структур, формирование нового типа руководителя-предпринимателя, действующего на принципах горизонтальных связей и деловой активности, интегрирование наиболее перспективных форм хозяйствования в экономику страны, выполнение на этой основе социально значимых проектов и программ»². Далее - выдержки из интервью одного из руководителей молодежных центров: «Сейчас только молодежные центры не отказались от работы с детьми и подростками, которых потеряли в погоне за доходами. Мы обязательно будем участвовать в фондах Милосердия, Детском, Культуры, Экологическом и др. Будем развивать и производственную деятельность, но для последующих вложений опять-таки в социальные программы...» (Зачем ... , 1989). В 1989-1990 годах создавалась и начала активно реализовываться Всесоюзная комплексная программа «Молодежь и культура», попечителями которой стали Советский фонд культуры, ЦК ВЛКСМ, Министерство культуры СССР, ВООПИК, ВЦСПС, Союз учителей и другие организации. Среди ее задач были, в том числе, создание центров эстетического воспитания, краеведческого направления, развитие программ молодежного туризма с уклоном

\footnotetext{
1 Личный архив А. А. Мелитоняна.

2 Там же.
} 
в историко-культурную и краеведческую направленность, проведение смотров, фестивалей, выставочной деятельности, создание музеев реалистического и современного искусства, поддержка инновационного творчества, содействия деятельности молодежных инновационных формирований...» ${ }^{1}$. В ряде документов констатировалось, что «принципиальным положением при применении хозрасчета в сфере культуры «является не только соизмерение затрат и результатов, но и соизмерение соотношения между затратами и результатами, направленными на удовлетворение индивидуальных и общественно-необходимых потребностей» ${ }^{2}$.

А вот пример иного рода: письмом от 20.12.1989 г. еще не получившая государственного статуса АСЭР поддержала «инициативу по созданию общественно-государственной службы в зонах аварий, катастроф и стихийных действий» ${ }^{3}$, прообраза Министерства Российской Федерации по делам гражданской обороны, чрезвычайным ситуациям и ликвидации последствий стихийных бедствий.

Непонимание или заведомое принижение роли консолидированных не только совместным бизнесом, но, прежде всего, основополагающими нравственными принципами целей деятельности мощных инновационных структур, которыми могли стать поддержанные государством объединения и ассоциации молодежных центров, хозяйствующих организаций и предприятий, явилось, на мой взгляд, одной из причин последовавшей в начале-середине 1990-х годов частичной криминализации бизнеса и развития коррупции в нашей стране. Превалирование коммерческой выгоды над решением социальных задач и решение социальных проблем не за счет создания условий для развития и всемерной поддержки социально ориентированного бизнеса, а за счет самого населения, мы видим и сегодня. Конечно, существование системы молодежных центров и иных, трансформировавшихся из «комсомольских» предприятий саморегулирующихся инновационных социально ориентированных организаций и их союзов не смогло бы полностью предотвратить все негативные процессы, связанные с лавинообразной коммерциализацией, но, в том, что подобные структуры смогли бы их смягчить, нет никаких сомнений.

\section{СПИСОК ЛИТЕРАТУРЫ}

Горбачев, М. С. (1987) Выступление на ХХ съезде ВЛКСМ // Московская правда. 17 апреля.

Зачем молодёжи своя экономика? (1989) // Московский комсомолец, 19 октября.

Идти вместе дорогой перестройки. Выступление М. С. Горбачёва перед делегатами XXI съезда ВЛКСМ. Ответы М. С. Горбачева на вопросы делега-

\footnotetext{
${ }^{1}$ Программа «Молодежь и культура». Личный архив А.А. Мелитоняна.

2 Личный архив А.А. Мелитоняна.

${ }^{3}$ Там же.
} 
тов съезда. 10 апреля 1990 г. (1990) М. : Политиздат.

Кононов, В. М. (1988) Развитие социальной инициативы молодежи в условиях совершенствования социализма : автореф. дис. ... к-та филос. н. М. Лямин, С. (1989) Комсомольская экономика // Молодой коммунист. № 2. С. 39.

Мелитонян, А. А. (1996) Развитие социально-культурных инициатив молодежи. М. : Институт молодёжи.

Мелитонян, А. А. (1997) Развитие социально-культурных инициатив молодежи в период перестройки советского общества (1985-1991 гг.) : автореф. дис. ... к-та ист. н. М.

Мелитонян, А. А. (2005) Молодежь и реализация социально-культурных инноваций (1985-1991 гг.). Опыт историко-культурного анализа / под общ. ред. А. А. Королева. М. : Изд-во Моск. гуманит. ун-та.

XX съезд ВЛКСМ. Стенографический отчёт. М. : Молодая гвардия. Т. I. Дата поступления: 30.08.2018 2.

Мелитонян Арсен Аркадьевич - кандидат исторических наук, президент Союза филокартистов России, г. Москва. Эл. адрес: russian-postman@ yandex.ru

Melitonyan Arsen Arkadyevich, Candidate of History, President, Russian Postcard Union, Moscow. E-mail: russian-postman@yandex.ru

\section{Для цитирования:}

Мелитонян А. А. «Молодежная» или «комсомольская» экономика: взгляд через 30 лет [Электронный ресурс] // Научные труды Московского гуманитарного университета. 2018. № 6. URL: http://journals.mosgu.ru/trudy/ article/view/836 (дата обращения: дд.мм.гг.). DOI: 10.17805/trudy.2018.6.5 